\title{
Using Web Content Management Systems in University E-Commerce Courses
}

\author{
$\underline{\text { doi:10.3991/ijet.v5s2.1249 }}$ \\ S. Mohorovičić, E. Tijan and D. Čišić \\ University of Rijeka, Rijeka, Croatia
}

\begin{abstract}
The aim of this paper is to elaborate and present the advantages of using Web Content Management Systems (primarily Joomla!) in e-commerce courses at universities. E-commerce is taught to many non-IT students who possess various previous knowledge in IT, which can often cause problems. Content Management Systems can circumvent those problems by avoiding the need for teaching HTML, PHP, SQL etc, and enabling non-IT students to focus on content management which is crucial for e-commerce. Characteristics of Web Content Management Systems are explained, followed by brief explanation of Joomla!. Examples are presented, along with experiences from the university.
\end{abstract}

Index Terms - Content Management Systems, e-commerce courses, Joomla!

\section{INTRODUCTION}

Having a web site is a very important part of today's business, especially if a company is involved in some type of commerce. Having a functional web site is only a first among many steps to e-commerce. Numerous universities have e-commerce courses but not all of them focus on the practical part of constructing and maintaining a funcional e-commerce web site. If an e-commerce or an e-business course is taught to students with little or no IT background (non-IT students), it becomes hard to present e-commerce web site concepts to them without extensive introduction to HTML, PHP, SQL etc. That is why Joomla! Web Content Management System was introduced into an ebusiness course at the University of Rijeka, Faculty of Maritime Studies.

\section{CONTENT MANAGEMENT Systems}

A Content Management System (CMS) is a tool that enables various technical and non technical staff to create, edit, manage and finally publish (in a number of formats) a variety of content (such as text, graphics, video, documents etc), whilst being constrained by a centralized set of rules, processes and workflows that ensure coherent, validated electronic content [1]. Several types of Content Management Systems currently exist, for example Enterprise Content Management Systems, Component Content Management Systems etc, but only Web Content Management Systems will be the subject of this paper. In short, a Web Content Management System is a CMS designed to simplify the publication of web content to web sites, in particular allowing content creators to submit content without requiring technical knowledge of HTML (hypertext markup language) or the uploading of files [2].
Web Content Management System completely separates the content of the pages from the pages' graphical design. Therefore, easy changes in design of the web site are possible, along with easy addition and editing of the content, even for people less skilled in the IT field. Because of the stated advantages, an increasing number of today's web sites is constructed and maintained by using Web Content Management Systems.

In the beginning, web sites were constructed in a way in which both content and instructions regarding the display of such content were present in the same file. Even today a number of web sites are being built and maintained the same way. If an author wanted to change some aspect of a web site's appearance (heading color, for example), he/she would need to change such appearance in every single web page within a site. Another large drawback of such a system is very large data files. In time, Cascading Style Sheets (CSS) were introduced. Cascading Style Sheets are used for visual presentation of a web site. All the relevant information needed for the presentation of web pages is stored in a separate file, away from the page content itself.

On the other hand, web sites developed using Content Management Systems are referred to as dynamic web sites. In development of a dynamic web site by using CMS, non-technical people can insert and edit content without interfering with web site's design. In other words, dynamic web pages are generated semi-automatically, after insertion of content. Table I shows the difference between static web sites and web sites created by using Content Management System (dynamic).

As mentioned above, HTML and CSS are complicated to majority of people who are not directly involved in Information Technologies (IT), and so is the case with non-IT students who are enrolled in e-commerce courses.

TABLE I.

COMPARISON OF STATIC WEB SITES AND CONTENT MANAGEMENT SYSTEMS [3]

\begin{tabular}{|l|l|}
\hline \multicolumn{1}{|c|}{ Static web site } & \multicolumn{1}{c|}{ Content Management System } \\
\hline $\begin{array}{l}\text { Easy to create initial } \\
\text { web pages }\end{array}$ & $\begin{array}{l}\text { To create initial pages is time-consuming as a } \\
\text { large script must be installed, databases set } \\
\text { up, and templates created }\end{array}$ \\
\hline $\begin{array}{l}\text { Content is static; } \\
\text { changing it requires } \\
\text { technical expertise }\end{array}$ & $\begin{array}{l}\text { Content is dynamic; it can be changed with } \\
\text { no technical knowledge }\end{array}$ \\
\hline $\begin{array}{l}\text { Difficult to add new } \\
\text { functions, often needs } \\
\text { custom code }\end{array}$ & $\begin{array}{l}\text { Most CMSs have many extensions that "plug } \\
\text { in" easily }\end{array}$ \\
\hline
\end{tabular}


It would involve a great deal of time and effort to deliver such knowledge to non-IT students in order to enable them to create web sites. Furthermore, as explained earlier, maintenance of such a web site would be much slower. If a more complicated web site is desired, it would involve the knowledge of several programming languages such as PHP (scripting language), SQL (Structured Query Language used for database management) etc. Content Management Systems can save time and effort - it is easy to construct a complex and powerful web site without the need of knowing HTML, CSS, PHP, SQL etc.

A variety of commercial and free Web Content Management Systems exist. The top open source CMSs that dominate the present market are Joomla!, Drupal and WordPress [4]. Joomla! and Drupal are often compared, and both have a strong army of followers. Joomla! is more common and widespread, simpler for beginners and has more available extensions. Furthermore, Joomla! has a very intuitive administration user interface and simple content editing. For that reason, Joomla! was chosen by authors as the more suitable choice for use in higher education.

\section{JOOMLA! - BRIEF HISTORY AND CHARACTERISTICS}

Joomla! is an open source Web Content Management System utilizing PHP and MySQL. It is released under the GNU General Public License. Joomla! is one of the most powerful open source Content Management Systems on the planet. It is used all over the world for everything from simple web sites to complex corporate applications. Joomla! is easy to install, simple to manage, and reliable [5].

Joomla! version 1.0. was released in September of 2005, but its roots go to 2001, when Australian company Miro Construct Pty Ltd developed a Content Management System called Mambo. In the beginning Mambo was open source, but in 2002 it was divided into two parts: comercial version called Mambo CMS and open source version called Mambo Open Source (MOS). Mambo Open Source became widely known simply as Mambo. It developed very quickly and won many prestigious open source awards. In 2005 a non-profit organisation was established, the Mambo Foundation, to protect and steer Mambo development. Due to disagreements with the Mambo Foundation, open source developers of Mambo left the Mambo project and established a new non-profit organisation called Open Source Matters. They continued to develop their Content Management System under a new name: Joomla!. The first release was very similar to the contemporary Mambo, so most of the extensions were compatible. In 2007 Joomla! 1.5 was released, significantly reducing the compability between Joomla! and Mambo.

Thanks to the massive online community, along with numerous free and commercial extensions, Joomla! quickly became one of the most popular open source Content Management Systems. The name "Joomla!" is derived from the Swahili and Urdu word "jumla", meaning "all together". Joomla! is used for various purposes: from development of basic personal web sites to complex web sites like e-commerce applications and community-based portals.

Compared with other Content Management Systems that can be very complex, Joomla! is probably the easiest to setup among all currently available Content Manage- ment Systems, allowing users of modest technical skill to harness its power [3]. That is precisely the reason why Joomla! was used in delivering e-commerce courses to non-IT students at the Faculty of Maritime Studies, Rijeka, Croatia, which will further be explained in the following paragraphs.

\section{JOOMLA! IN PRACTICE}

A typical Joomla! installation comes with some preinstalled templates. Those templates and their associated files provide the visual "look and feel" of the web site and are maintained separately from the web site's content. When installing, the option to install sample data is given. It is recommended that beginners choose this option to view already prepared examples, try to change them and add new content. Figure 1 shows the Joomla! frontend.

Components are basic elements of Joomla!'s functionality and are displayed in the main body of the web site's template. Depending on the design of the template in use, this is often in the center of the web page. A typical Joomla! installation comes with Banners, Contacts, News Feeds, Polls and Web Links components.

Once installed, the web site administrator (also known as the Super Administrator who has control over all aspects of a Joomla! web site administrator's panel) can login to the backend administration console shown in Figure 2 and set up sections, categories, content items, polls and much more; administrating the entire frontend of the web site from a point and click interface.
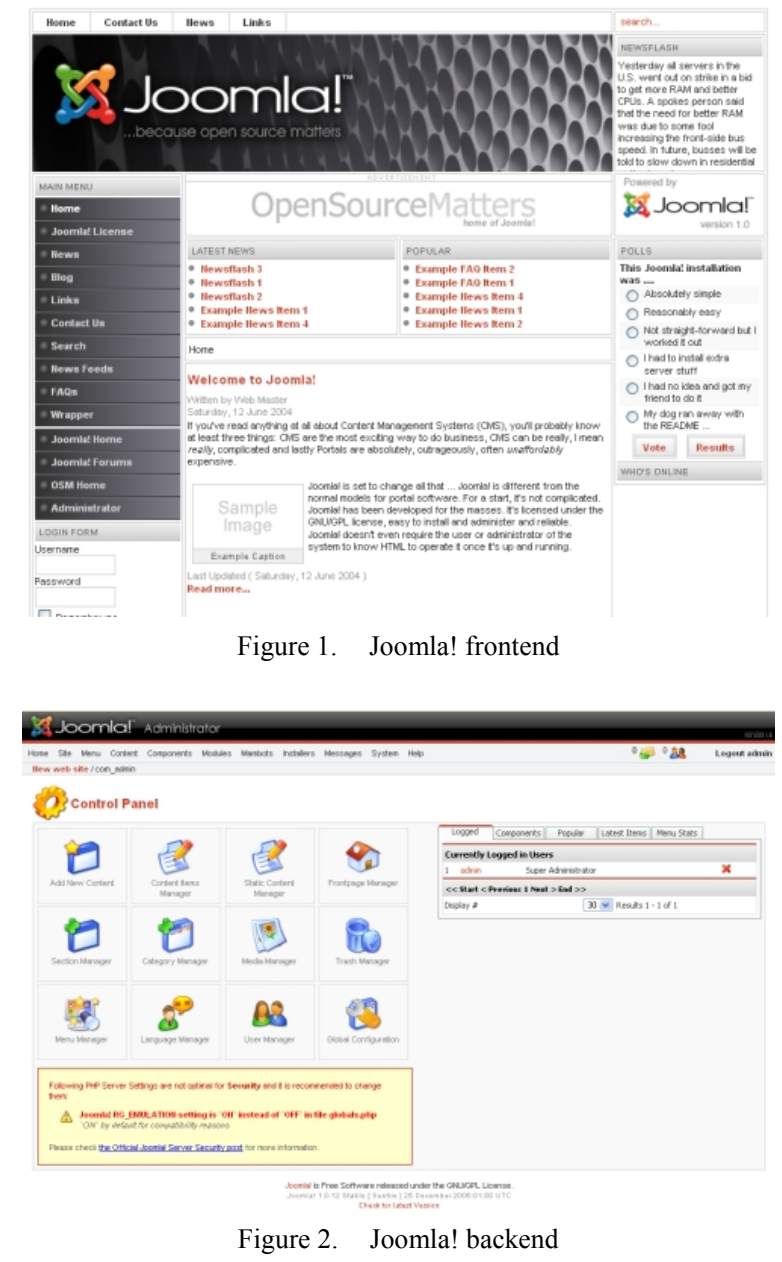
When the content is created, a WYSIWYG (What You See Is What You Get) editor allows simple editing without the knowledge of HTML [6]. Figure 3 shows a screenshot of editing a Content Item in a web site.

Some of the extensions included in base installation are polls, public site statistics, site search and simple content rating system. A large number of free and commercial extensions exist, created by non-official developers. More than 4400 extensions are available in the official repository (http://extensions.joomla.org/). With the appropriate extensions (for example galleries, forums, shopping carts etc.), a powerful e-commerce web site can be constructed; a lot more than simple personal or hobby web sites. On the web, e-commerce has become big business - particularly for B2B (business to business) transactions. To tap into the worldwide customer base that the Internet makes available, you can configure your Joomla! site to allow for online purchases or catalog display [7]. Joomla! web sites can easily be upgraded with various e-commerce additions, such as before mentioned shopping carts for example.

A localized Croatian version of Joomla! exists, along with some extensions [8]. However, it is less stable than the original (English) version, therefore it was not used by the authors in delivering their e-business course. Unanimous decision was reached that English version will be used, not only for stability reasons but also for the benefit of the students' knowledge of the English language.

For learning purposes, local installation of Joomla! proved to be most practical. In this setup, Joomla! is installed on every computer locally, so there is no need for an Internet connection. For successful instalation and use Joomla! has some system requirements: PHP, MySQL and Apache. To be able to install Joomla! for local testing, all of the above have to be installed. The hardest way is to install each of the components separately and configure them to work together. Various packages for the various operating systems exist that satisfy such demands, for example XAMP and JSAS (Joomla! Stand Alone Server).

XAMP's name is an acronym for $\mathrm{X}$ (meaning crossplatform), Apache HTTP Server, MySQL and PHP. XAMP is a web server package for various operating systems. Using Joomla! Stand Alone Server is even easier. JSAS is a WAMP (Windows/Apache/MySQL/PHP) stand alone server with Joomla! preinstalled [9].

\section{EXPERIENCES FROM THE UNIVERSITY}

E-commerce and E-business courses have been taught for several years at the University of Rijeka, Faculty of Maritime Studies by full professor Dragan Čišić, PhD. Within such courses students were introduced to Ebusiness fundamentals, Business Analysis and Development, E-payments, E-Business Modeling, Internet Marketing, Customer Relationship Management, Business Intelligence, Mobile Commerce, software for E-Business etc. During the laboratory exercises, students learned how to create and manage a web site powered by Joomla!. The main idea for such a type of exercise was devised after reading the following statement: "Anybody with basic word processing skills can easily learn to manage a Joomla! web site [10]".

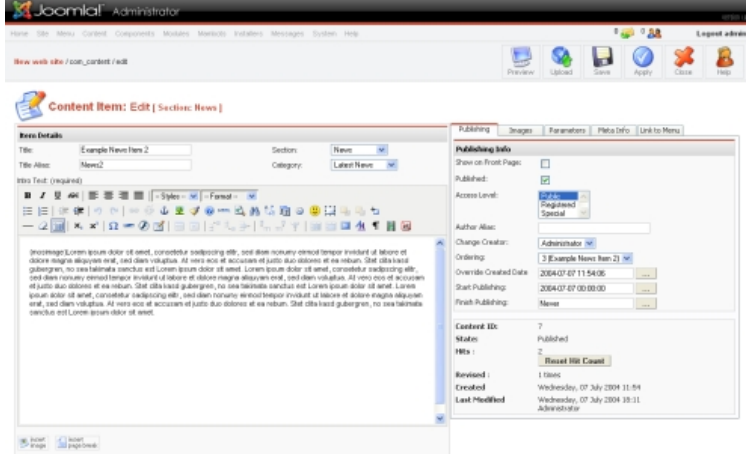

Figure 3. Editing a Content Item in Joomla! web site

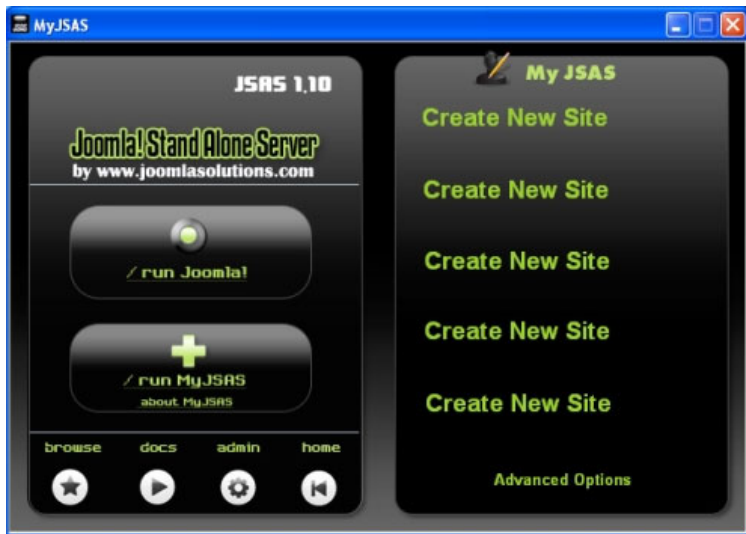

Figure 4. Joomla! Stand Alone Server

As mentioned above, due to the simplicity of local installation of up to 5 web sites at the same time, Joomla! Stand Alone Server version 1.10.2 was used (see Fig. 4).

Joomla! Stand Alone Server version 1.10.2 contains Joomla! v.1.0.12, MySQL v.4.1.14, phpMyAdmin v.2.8.2.4, PHP v.4.4.4 and Apache v.2.2.3

With only one installation file of about $23 \mathrm{MB}$ in size all of the neccessary components can be installed, enabling students to install Joomla! and work with it at home. Unfortunately, the new version (JSAS v.1.10.5.3) containing Joomla! v.1.5 requires payment via Charter Membership, therefore an older and free version has been used. Such fact is not that important, because the students can still effectively learn how to create and manage a web site using the older (free) version.

During the laboratory exercises students were introduced to the structure of Joomla!: frontend and backend, access rights, content, extensions (components, modules, plug-ins, templates), configuration settings etc. lows:

The practical part of the course was structured as fol-

- Basic HTML - writing basic code (Notepad)

- FrontPage basics - WYSIWYG editor

- Content Management Systems and Joomla! description

- Joomla! Stand Alone Server installation

- Web site creation

- Logging in and out

- Viewing the site from frontend and backend, basic Joomla! characteristics

- Adding content: creating sections, categories and content items (articles), creating static content 
- Content deletion

- Adding pictures via Media manager and using them in sections, categories and articles

- Adding links on menus, creating new menus, editing menus

- Administration of the site's front page

- Polls viewing and editing, adding new polls

- Site templates and administrator templates download, installation, usage

- User management - adding new users with different authorization levels, viewing and changing, comparison between administration and lower level users

- Banners - creation, adding, editing

- Global configuration

- Contacts

- Mass mail

- Croatian language for frontend

- Extensions - explanation (component, module, mambot/plug-in), download and installation. For example:

o BookJoomlas guestbook (component)

o Random Simpsons Quotes (module)

o Productbook catalogue (component) - creating product categories, adding product pictures with information and prices

o zOOm Media Picture Gallery (component)

At the end of semester, students were required to construct and present their own web sites. They had a freedom of choice regarding the content of their web sites. Below are only a few examples of the students' web sites:

- Overseas travel agency (Australia)

- Buggy world - (ATV \& quad vehicles)

- Car dealership and Honda Fan Club

- Online shoe store

- Online jewelry store

- Perfumes - portal with information on perfumes

- New mobile phone operator

- GPS navigational devices

- My Mobile - mobile phone web site

- City tourist board web site

- Real estate - selling and renting

- Hunting web site - info, regulation, weapons...

- New insurance company

- Boats, yachts and sailing

- Recreation and free time

- Driving school web site

Figure 5 shows the home page of one such web site. At a first glance, such web sites are aesthetically equal to a large number of professional web sites.

At the end of the semester a questionnaire was circulated among students in order to explore their views and opinions regarding the course in which they have just participated. More than $80 \%$ of the students commented on the simplicity of Joomla! as a tool. Majority of them had no trouble whatsoever getting used to the friendly interface. At the beginning, some students had trouble understanding the web site as a group of content (Section/Category/Content Item hierarchy and Static Content Item) and not a group of individual web pages, but they quicky became familiar with the concept.

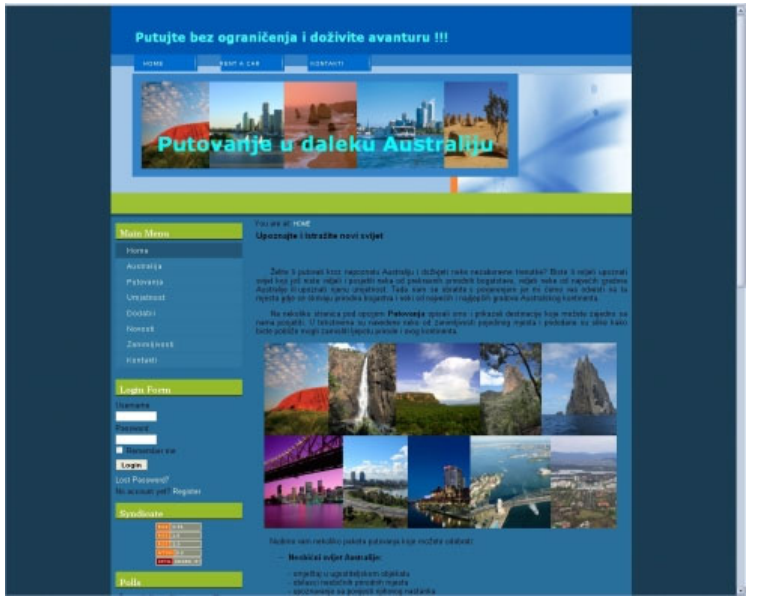

Figure 5. Example of a student's web site constructed during an ebusiness course

$95 \%$ of the students thought that the knowledge they recieved during the course could be usable for them in the future. A few students even decided to try constructing web sites profesionally, as more than a hobby. Large number of students continued to ask questions about Joomla! even after completing and passing the course, which clearly shows that delivering an e-business course in such a way was a very good idea.

There were some drawbacks, however. It was difficult to conduct exercises in the computer laboratory due to insufficient number of available computers. The review of the completed web sites was time consuming, since every student brought his/her web site to the teacher on CD or USB memory stick. The web site (the complete JSAS) installation and review had to be performed on teacher's computer. This problem was somewhat facilitated by encouraging students who own portable computers to bring and present their work directly from their own computer.

Following are only a few statements regarding the ebusiness course from the students' questionnaires:

- "Given the fact that I'm not an IT student and I don't know anything about web programming and web design, I can tell that this tool is really simple and straightforward to use, yet creative enough to allow students to express their ideas"

- "I would definitely reccommend this tool because it is really simple for beginners, but it has more than enough features"

- "I always thought that web design was reserved for "computer smart" people, and I wasn't one of them. I was very wrong. Even I can create a good web site"

- "This is a refreshment from the classical book based learning to which we are used to. Prof. Čišić showed us that any of us can design a functional e-commerce web site, even without previous knowledge"

- "I will definitely try this at home, and I hope to make some money designing web sites"

- "After seeing what I did in class, my boyfriend and a lot of my friends asked me to build their personal web sites"

\section{CONCLUSION}

For the purpose of delivering an e-business or an ecommerce course in higher education (colleges and universities), it is imperative that students understand how e- 
commerce web sites work, how they are designed, constructed and maintained. Given the complexity of the subject (involvement of HTML, PHP, CSS, SQL etc.) the concept of an e-commerce web site can really be hard to understand for student population which is not very well versed in Information Technologies. Content Management Systems proved to be a valuable solution to such a problem because they are intuitive and easy to use. Combined with other neccessary components into Stand Alone Servers, Content Management Systems enable students with virtually no IT background to construct and maintain aesthetically pleasing and functional e-commerce web sites.

For an e-business course at Faculty of Maritime Studies, University of Rijeka, Joomla! (simple, powerful, user friendly, intuitive and free) and Joomla! Stand Alone Server were used in the past three years with great success. Students were very satisfied with the course and went out of their way to construct functional e-commerce web sites. Majority of students chose to enroll in the course (it was not obligatory for most of them), larger than average number of them passed the course (with above than average grades) and continued to express their interest in the subject even after successfully passing the course.

A large number of templates and extensions (components, modules and plug-ins) added to the overall usability of the used Content Management System, increasing the students' interest for the subject. Since the students worked off line (locally), there was no need for a host server and its administration, which effectively reduced the costs associated with delivering such a course. Overall conclusion from both students and professor/assistants was that using Joomla! definitely enabled the students to better understand the concepts of e-commerce. Answers and data from the students' questionnaires strongly suport that statement.

\section{REFERENCES}

[1] What is a Content Management System, or CMS?, http://www.contentmanager.eu.com/cms.htm (25.11. 2008.)

[2] Content management system, http://en.wikipedia.org/wiki/ Content_management_system $(27.11 .2008$.)
[3] B. M. North, Joomla! A User's Guide: Building a Successful Joomla! Powered Web site, Prentice Hall, New Jersey, 2008

[4] R. Shreves, The 2008 Open Source CMS Market Share Report, Published by Water\&Stone, http://www.waterandstone.com/ resources.html (05.12.2008.)

[5] CMS Joomla!, http://www.smartsolutions.com.ua/1/joomla.htm (12.12.2008.)

[6] Joomlashack, http://www.joomlashack.com (15.12.2008.)

[7] D. Ramel, Beginning Joomla! From Novice to Professional, Apress, Berkeley, 2007.

[8] CroJoomla.com, http://www.crojoomla.com (17.12.2008.)

[9] JSASOnline, http://www.jsasonline.com (17.12.2008.)

[10] S. White, A. Wallace, The official Joomla! User Manual for 1.0.11, 2006. http://help.joomla.org/images/User_manual/user_manual_v1\%200 \%201 10\%2021\%2006.pdf (15.11.2008.)

[11] Comparing Open Source CMSes: Joomla, Drupal and Plone, http://www.idealware.org/articles/joomla_drupal_plone.php (10.01. 2009.)

[12] H. Graf, Building Web sites with Joomla!, Pact Publishing, Birmingham, 2006.

[13] H. Graf, Building Web sites with Joomla! 1.5, Pact Publishing, Birmingham, 2008.

[14] Joomla!, http://www.joomla.org (11.11. 2008.)

\section{AUTHORS}

S. Mohorovičić works as assistant at the University of Rijeka, Faculty of Maritime studies, Department of Electrical Engineering, Automatics and IT, Rijeka, Croatia (email:sanja@pfri.hr).

E. Tijan works as assistant at the University of Rijeka, Faculty of Maritime studies, Department of Logistics and Management, Rijeka, Croatia (e-mail: etijan@pfri.hr).

D. Čišić works as full professor at the University of Rijeka, Faculty of Maritime studies, Department of Logistics and Management, Rijeka, Croatia (e-mail: dragan@pfri.hr).

This article was modified from a presentation at The 32nd International Convention MIPRO on information and communication technology, electronics and microelectronics., in 25-29 May 2009, Opatija, Croatia. Manuscript received, 26 February 2010. Published as resubmitted by the authors 1st March 2010 